\title{
MLST and RAPD molecular analysis of Staphylococcus aureus subsp. anaerobius isolated from goats in Poland
}

\author{
Olga Szaluś-Jordanow ${ }^{1}$ (1) Katarzyna Krysztopa-Grzybowska² $\cdot$ Michał Czopowicz ${ }^{3} \cdot$ Agata Moroz $^{3}$. \\ Marcin Mickiewicz ${ }^{3} \cdot$ Anna Lutyńska $^{4} \cdot$ Jarosław Kaba $^{3} \cdot$ Tomasz Nalbert $^{3} \cdot$ Tadeusz Frymus $^{1}$
}

Received: 4 May 2018 / Revised: 16 August 2018 / Accepted: 29 August 2018 / Published online: 4 September 2018

(c) The Author(s) 2018

\begin{abstract}
Staphylococcus aureus subsp. anaerobius is an etiological agent of Morel's disease in small ruminants. The infection results in superficial abscesses located near lymph nodes. In the study, molecular analysis based on multilocus sequence typing (MLST) of seven housekeeping genes ( $\operatorname{arcC}$, aroE, glp, gmk, pta, tpi, yqiL) and random amplified polymorphic DNA (RAPD) was carried out on 19 S. aureus subsp. anaerobius strains isolated from two different goat herds from Poland. All of the 19 S. aureus subsp. anaerobius strains were found to belong to single MLST and RAPD types which support the high clonality level of this agent. However, the results obtained show clearly that the S. aureus subsp. anaerobius clone found in goats in Poland is different from those previously described. However, it is identical to the ATCC 38844 strain isolated from sheep in Spain, which has not been so far genotyped using MLST.
\end{abstract}

Keywords Staphylococcus aureus subsp. anaerobius $\cdot$ MLST $\cdot$ RAPD $\cdot$ Goat $\cdot$ Morel's disease

\section{Introduction and aim}

Staphylococcus aureus subsp. anaerobius is a Gram-positive, coccus-shaped bacterium growing typically at $37^{\circ} \mathrm{C}$ on 5\% sheep blood-enriched Columbia agar in microaerophilic conditions (de la Fuente et al. 1985). S. aureus subsp.

Communicated by Jorge Membrillo-Hernández.

Olga Szaluś-Jordanow

olga_szalus@sggw.pl

Katarzyna Krysztopa-Grzybowska

kkrysztopa@pzh.gov.pl

Michał Czopowicz

mczopowicz@gmail.com

Agata Moroz

moroz.agata@gmail.com

Marcin Mickiewicz

marcin.m157@gmail.com

Anna Lutyńska

a.lutynska@ikard.pl

Jarosław Kaba

jaroslaw_kaba@sggw.pl

Tadeusz Frymus

tadeusz_frymus@sggw.pl anaerobius causes Morel's disease in small ruminants, inducing subcutaneous abscesses measuring form several to $30 \mathrm{~cm}$ (Szaluś-Jordanow et al. 2010). Clinical signs are observed in young animals, mostly at the age of less than 6 months and rarely in adult ones (Møller et al. 2000). Morel's disease in goats is regarded as a rare or frequently misdiagnosed condition. The disease has been described in many countries, inter alia: Somali (Pegram 1973), Sudan

Division of Infectious Diseases, Department of Small Animal Diseases with Clinic, Warsaw University of Life Sciences-SGGW, Nowoursynowska 159c Street, 02-776 Warsaw, Poland

2 Department of Sera and Vaccine Evaluation, National Institute of Public Health-National Institute of Hygiene (NIPH-NIH), 24 Chocimska Street, 00-791 Warsaw, Poland

3 Laboratory of Veterinary Epidemiology and Economics, Warsaw University of Life Sciences-SGGW, Nowoursynowska 159 Street, 02-776 Warsaw, Poland

4 Department of Medical Biology, The Cardinal Stefan Wyszyński Institute of Cardiology, Alpejska 42 Street, 04-628 Warsaw, Poland 
(el Sanousi et al. 1989), Kenya (Shirlaw and Ashford 1962), Saudi Arabia (Alhendi et al. 1993), Italy (Valenti and Bielar 1984), Croatia (Habrun et al. 2004) and Poland (SzaluśJordanow et al. 2010). Availability of $S$. aureus subsp. anaerobius-sequenced genomes allows to apply molecular tools that might precisely differentiate this infection from that caused by atypical $S$. aureus subsp. aureus or other catalase-negative staphylococci (Elbir et al. 2013). Different molecular methods, such as genotyping, have been applied in inexpensive and fast tracking of the strain genetic similarity during epidemiological studies. Random amplified polymorphic DNA (RAPD) technique allowed to reveal genetic differences within many bacterial species (Gzyl and Augustynowicz 1999), however, had not been used before for genotyping of $S$. aureus subsp. anaerobius. The aim of this study was to perform a genetic analysis of $S$. aureus subsp. anaerobius strains isolated from goats in Poland using multilocus sequence typing (MLST) and compare its discriminatory potential to that of RAPD.

\section{Materials and methods}

In the study, molecular analysis was carried out on $19 S$. aureus subsp. anaerobius strains isolated from two goat herds from Poland. According to the information obtained from the goat's owner, transfer between the herds was made in the past. Reference strains of $S$. aureus subsp. anaerobius ATCC 35844 and S. aureus subsp. aureus ATCC 29213 bought directly from ATCC via http://www.lgcstandar ds.com/atcc were used in the study. According to the https ://www.lgcstandards-atcc.org/products/all/35844.aspx?geo_ country $=\mathrm{pl} \#$ documentation, ATCC 35844 strain was isolated from a young sheep in Spain (de la Fuente et al. 1985).

Strains were cultured on Columbia agar with 5\% sheep blood and incubated for $48 \mathrm{~h}$ at $37{ }^{\circ} \mathrm{C}$ in aerobic and microaerophilic conditions. Chromosomal DNA was isolated using commercially available kit modified by the inclusion of lysostaphin (SIGMA).

MLST of seven housekeeping genes: carbamate kinase $(\operatorname{arc} C)$, shikimate dehydrogenase (aroE), glycerol kinase $(\mathrm{glp})$, guanylate kinase $(\mathrm{gmk})$, phosphate acetyltransferase (pta), triosephosphate isomerase (tpi), and acetyl coenzyme A acetyltransferase (yqiL) were performed according to Enright et al., 2000 with small modifications. PCR was carried out with $20-\mu$ reaction volumes containing $20 \mathrm{ng}$ of DNA, 20 pmol of each primer and $10 \mu \mathrm{l}$ of JumpStart REDTaq ReadyMix PCR Reaction Mix (SIGMA), and performed with an initial denaturation $\left(95^{\circ} \mathrm{C} / 5 \mathrm{~min}\right)$ followed by 30 cycles of denaturation $\left(95^{\circ} \mathrm{C} / 30 \mathrm{~s}\right)$, annealing $\left(55^{\circ} \mathrm{C} / 30 \mathrm{~s}\right)$, extension $\left(72{ }^{\circ} \mathrm{C} / 45 \mathrm{~s}\right)$ followed by a final extension step ( $72{ }^{\circ} \mathrm{C} / 5 \mathrm{~min}$ ). Sequencing of both strands was performed by external service (Genomed S.A.). Analysis of the sequencing results and classification of MLST types was performed using the database available at https://pubmlst.org/saureus/.

Random amplified polymorphic DNA reaction was performed using Ready-To-Go RAPD analysis beads (GE Healthcare Life Sciences). Each bead containing buffer, dNTPs, bovine serum albumin and thermostable DNA polymerase was mixed with $20 \mathrm{ng}$ of DNA, $25 \mathrm{pmol}$ of Primer 6 (5'-d[CCCGTCAGCA $\left.]-3^{\prime}\right)$ and $\mathrm{H}_{2} \mathrm{O}$. PCRs were performed with an initial denaturation $\left(95^{\circ} \mathrm{C} / 5 \mathrm{~min}\right)$ followed by 45 cycles of denaturation $\left(95^{\circ} \mathrm{C} / 1 \mathrm{~min}\right)$, annealing $\left(36^{\circ} \mathrm{C} / 1 \mathrm{~min}\right)$, extension $\left(72{ }^{\circ} \mathrm{C} / 2 \mathrm{~min}\right)$ followed by a final extension step $\left(72{ }^{\circ} \mathrm{C} / 2 \mathrm{~min}\right)$. RAPD profiles were analyzed using BioNumerics Software (6.6, Applied Maths) according to the UPGMA algorithm with the Pearson's coefficient.

\section{Results}

All 19 S. aureus subsp. anaerobius strains and the ATCC 35844 strain were found to be single MLST and RAPD profile types. RAPD analysis showed $>95 \%$ genetic similarity among the tested isolates (Fig. 1). According to the MLST database, all strains were assigned as harboring the MLST-type ST4581 (102, 219, 204, 122,13, 422, 502) that differs by three substitutions in the tpi and yqiL genes from the widely described in the literature ST1464 type (Fig. 1). Analysis of sequences available in the https://pubmlst.org/ saureus/ database revealed high similarity of our MLST type to the ST3756 type isolated from sheep in the Czech Republic, as they differ only by a single nucleotide polymorphism in the pta gene.

\section{Discussion and conclusions}

Several publications from other countries suggested high genetic homogeneity of $S$. aureus subsp. anaerobius isolates. Musa et al. (2010) found this in the sequences of catalaseencoding gene as they identified only a single mutation typical for African strains in comparison with European isolates. European and African strains have been found to share 13-15 mutations in the kat gene, and these subtle differences were regarded by de la Fuente et al. (2011) as related to the host adaptation. Elbir et al. (2013) found all 17 caprine $S$. aureus subsp. anaerobius strains from Sudan to harbor a single MLST-type ST1464, confirming high subspecies clonality. Similarly, MLST data obtained by de la Fuente et al. (2011) for 94 strains of $S$. aureus subsp. anaerobius isolated from small ruminants in Spain $(n=79)$, Italy $(n=9)$, Denmark $(n=3)$ and Sudan $(n=3)$ confirmed high genetic homogeneity as seen by PFGE and sharing of the same ST1464 type of MLST. In our study, we found that the goats in two Polish herds were infected with a single $S$. 
Fig. 1 RAPD and MLST analysis of the 19 clinical $S$. aureus ssp. anaerobius isolates and two reference strains

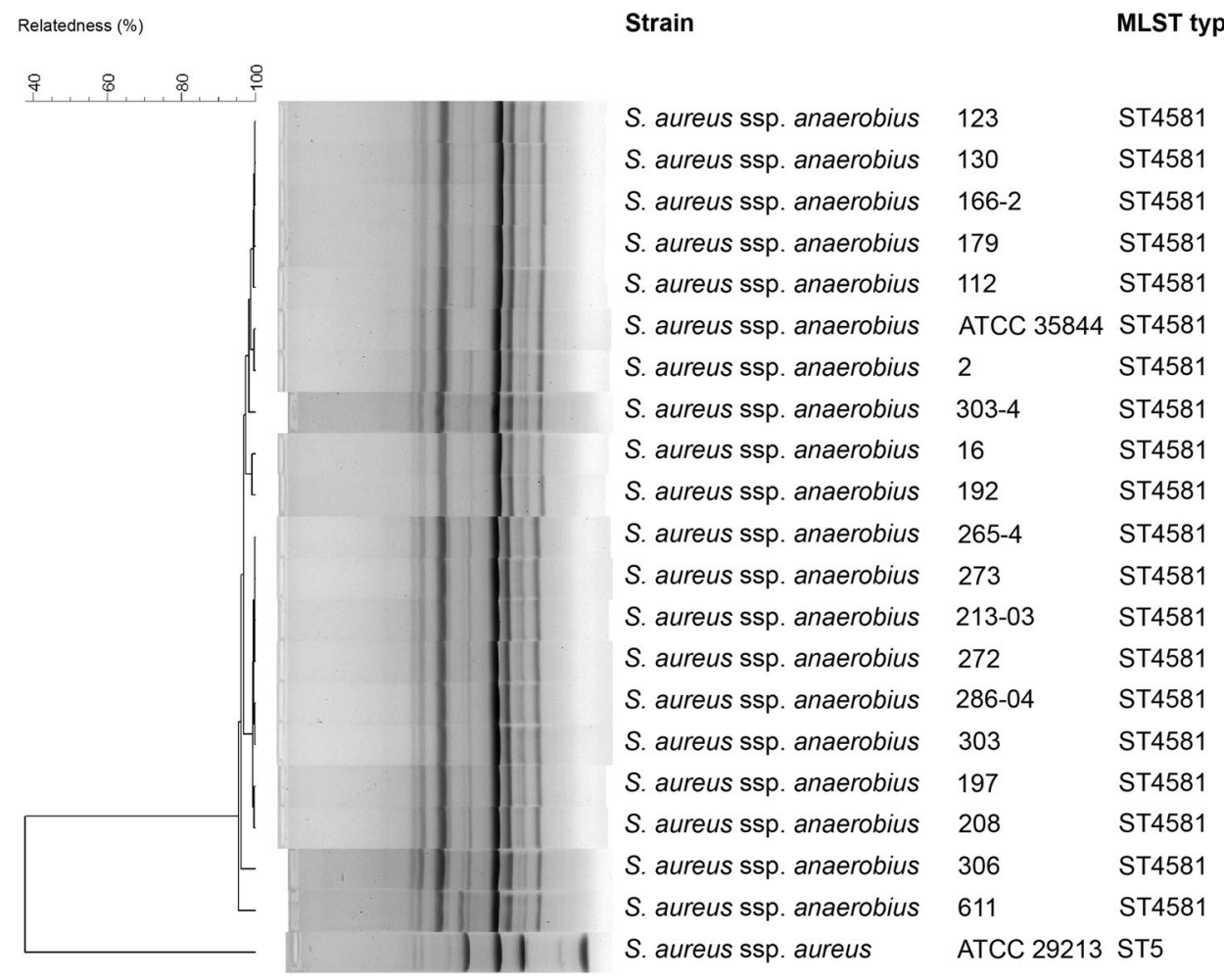

aureus subsp. anaerobius MLST clone assigned as ST4581 (Fig. 1). This MLST type is very similar to ST1464, commonly found in strains isolated worldwide, differing only by three point mutations. Furthermore, ST4581 found in our goats differs from a strain isolated in the Czech Republic by only one point mutation in the pta gene (ST3756). The Czech Republic is the neighbor country of Poland, with a border in the mountains, and exchange of small ruminants between flock owners could have taken place in the past. Further studies on whole genome sequences of strains originating from Poland and the Czech Republic might elucidate the character of changes in the view of the thesis of country specific host adaptation of isolates involved in Morel disease in small ruminants.

In conclusion, our finding supports previous findings about high genetic homogeneity of $S$. aureus subsp. anaerobius isolates. The MLST clone ST4581 variations found in this study have not been described elsewhere. However, it is identical to the ATCC 38844 strain isolated from a sheep in Spain. Thus far, this reference strain has not been genotyped with MLST method. As seen in Fig. 1, both MLST and RAPD were capable to differentiate the aureus and anaerobius substrains of $S$. aureus. As we described before (Szaluś-Jordanow et al. 2010), one animal with asymptomatic infection is sufficient to introduce the disease into a herd. In our case it was a male goat bought from Germany. It is possible that Morel's disease is widespread in Europe, however, remains misdiagnosed for caseous lymphadenitis caused by Corynebacterium pseudotuberculosis. In Germany, where the male goat came from, Morel's disease had not been even described.

Abscess disease was additionally confirmed to be a clonally spread as genetic similarity of analysed strains measured by RAPD fingerprinting was almost identical which is consistent with earlier studies (Szaluś-Jordanow et al. 2011, 2013).

Funding The present work was financially supported by Laboratory of Veterinary Epidemiology and Economic, Faculty of Veterinary Medicine, Warsaw University of Life Sciences-SGGW. Publication was funded by KNOW (Leading National Research Centre) Scientific Consortium "Healthy Animal—Safe Food", decision of Ministry of Science and Higher Education No. 05-1/KNOW2/2015.

\section{Compliance with ethical standards}

Conflict of interest The authors have no conflicts of interest.

Open Access This article is distributed under the terms of the Creative Commons Attribution 4.0 International License (http://creativeco mmons.org/licenses/by/4.0/), which permits unrestricted use, distribution, and reproduction in any medium, provided you give appropriate credit to the original author(s) and the source, provide a link to the Creative Commons license, and indicate if changes were made. 


\section{References}

Alhendi AB, al-Sanhousi SM, al-Ghasnawi YA, Madawi M (1993) An outbreak of abscess disease in goats in Saudi Arabia. Zentralbl Veterinarmed A 40:646-651

De la Fuente R, Suarez G, Schleifer KH (1985) Staphylococcus aureus subsp. anaerobius subsp. nov., the causal agent of abscess disease of sheep. Int J Syst Bacteriol 35:99-102

De la Fuente R, Ballesteros C, Bautista V, Medina A, Orden JA, Domínguez-Bernal G, Vindel A (2011) Staphylococcus aureus subsp. anaerobius isolates from different countries are clonal in nature. Vet Microbiol 150:198-202

El Sanousi SM, Hamad AA, Gameel AA (1989) Abscess disease in goats in the Sudan. Rev Elev Med Vet Pays Trop 42:379-382

Elbir H, Robert C, Nguyen TT, Gimenez G, El Sanousi SM, Flock J-I, Raoult D, Drancourt M (2013) Staphylococcus aureus subsp. anaerobius strain ST1464 genome sequence. Stand Genomic Sci 9:1-13

Enright MC, Day NP, Davies CE, Peacock SJ, Spratt BG (2000) Multilocus sequence typing for characterization of methicillin-resistant and methicillin-susceptible clones of Staphylococcus aureus. J Clin Microbiol 38:1008-1015

Gzyl A, Augustynowicz E (1999) Technical aspects of random amplified polymorphic DNA (RAPD) technique in genotyping of bacterial strains. Acta Microbiol Pol 48:243-259

Habrun B, Listeš E, Kompes G, Cvetnić Ž, Mitak M (2004) Abscess forming lymphadenitis of goats and sheep. Vet Stanica ZnanStručni Vet Časopis 35:139-144

Møller K, Agerholm JS, Ahrens P, Jensen NE, Nielsen TK (2000) Abscess disease, caseous lymphadenitis, and pulmonary adenomatosis in imported sheep. J Vet Med B Infect Dis Vet Public Health 47:55-62

Musa NO, Eltom K, Gessler F, Böhnel H, Babiker A, Sanousi E, S.M (2010) The catalase gene differentiates between some strains of Staphylococcus aureus ssp. anaerobius. Folia Microbiol (Praha) $55: 211-214$

Pegram RG (1973) An unusual form of Lymphadenitis in sheep and goats in the Somali Democratic Republic. Trop Anim Health Prod 5:35-39

Shirlaw JF, Ashford WA (1962) The occurrence of caseous lymphadenitis and Morel's disease in a sheep flock in Kenya. Vet Rec 74:1025-1026

Szalus-Jordanow O, Kanbar T, Soedarmanto I, Eissa N, Alber J, Lämmler C, Zschöck M, Weiss R, Kaba J, Frymus T (2011) Phenotypic and genotypic properties of Staphylococcus aureus subsp. anaerobius isolated from lymph node abscesses of goats. Berl Munch Tierarztl Wochenschr 124(3-4):123-127

Szaluś-Jordanow O, Kaba J, Czopowicz M, Witkowski L, Nowicki M, Nowicka D, Stefańska I, Rzewuska M, Sobczak-Filipiak M, Binek M, Frymus T (2010) Epidemiological features of Morel's disease in goats. Pol J Vet Sci 13:437-445

Szaluś-Jordanow O, Chrobak D, Pyrgiel M, Lutyńska A, Kaba J, Czopowicz M, Witkowski L, Kizerwetter-Świda M, Binek M, Frymus T (2013) PFGE and AFLP genotyping of Staphylococcus aureus subsp. anaerobius isolated from goats with Morel's disease. Arch Microbiol 195(1):37-41

Valenti G, Bielar C (1984) Cultural and biochemical characteristics of strains of Morel's coccus responsible for abscesses in goats in the valleys of the Cuneo area. Ann Fac Med Vet Torino 28:286-307 